Котяш І. Реалізація екологічної компетентності майбутніх вчителів ...

УДК 377.8.011.3

DOI https://doi.org/10.24919/2308-4863/34-3-38

Ірина КОТЯШ,

orcid.org/0000-0002-3975-3339

аспірантка кафедри педагогіки та освітнього менеджменту Уманського державного педагогічного університету імені Павла Тичини (Умань, Черкаська область, Україна) irishka1112@ukr.net

\title{
РЕАЛІЗАЦІЯ ЕКОЛОГІЧНОЇ КОМПЕТЕНТНОСТІ МАЙБУТНІХ ВЧИТЕЛІВ ПОЧАТКОВИХ КЛАСІВ У ЗВ'ЯЗКУ ІЗ ВПРОВАДЖЕННЯМ КОНЦЕПЦӤ НОВОЇ УКРАЇНСЬКОЇ ШКОЛИ
}

\begin{abstract}
У статті розглядається актуальна проблема, яка пов'язана з формуванням екологічної компетентності вчителів початкових класів в контексті Нової української школи. На базі досвіду науковців проаналізовано поняття «компетентність» $i$ «екологічна компетентність». Висвітлено процес реалізації екологічної підготовки у педагогічному коледжі майбутніх вчителів початкових класів на основі впровадження і вивчення такого нового предмету, як «Методика навчання інтегрованого курсу “Я досліджую світ”», в якому приділено увагу формуванню екологічних знань, умінь та навичок, розвитку екологічного мислення та свідомості, формуванню екологічної культури та відповідної екологічної поведінки у природному середовищі, екологічної грамотності. Нині изе є дуже актуальним, бо ключовою фігурою у формуванні екологічної компетенції майбутніх поколінь завжди залишався вчитель. Тому під час фахової підготовки здобувачів освіти - майбутніх вчителів початкових класів на базі педагогічного коледжу, важливою є екологічна компетентність, зокрема готовність до природоохоронної та екологічної роботи з дітьми.

У роботі висвітлені особливості формування екологічної компетентності у майбутніх вчителів Нової української школи. Визначено методи та форми організачії навчальної діяльності під час вивчення такого предмету природничого ииклу, як «Методика навчання інтегрованого курсу “Я досліджую світ”" в умовах педагогічного коледжу. Сформовані систематичні підходи, професійно-орієнтовна діяльність, приниип доцільності та готовності до сприйняття екологічної освіти та рівні екологічної компетентності майбутніх вчителів початкових класів. Досліджено вплив інновачійних технологій під час вивчення інтегрованого курсу на стан екологічної компетентності майбутніх випускників педагогічного коледжу.
\end{abstract}

Ключові слова: компетентність, екологічна компетентність вчителів початкових класів, державний стандарт початкової освіти, Нова украӥнська школа, інтегрований курс «Я досліджую світ».

Iryna KOTIASH, orcid.org/0000-0002-3975-3339 Postgraduate Student at the Department of Pedagogy and Educational Management Pavlo Tychyna Uman State Pedagogical University (Uman, Cherkasy region,Ukraine) irishka1112@ukr.net

\section{IMPLEMENTATION OF ENVIRONMENTAL COMPETENCE OF FUTURE PRIMARY SCHOOL TEACHERS IN CONNECTION WITH IMPLEMENTATION OF THE CONCEPT OF THE NEW UKRAINIAN SCIENCE}

The article considers a topical issue related to the formation of environmental competence of primary school teachers in the context of the New Ukrainian School. Based on the experience of scientists, the concepts of "competence" and "environmental competence" are analyzed. The process of implementation of environmental training in the pedagogical college of future primary school teachers based on the introduction and study of a new subject, as "Methods of teaching an integrated course" "I explore the world", which focuses on the formation of environmental knowledge, skills, development of environmental thinking and consciousness. formation of ecological culture and corresponding ecological behavior in the natural environment, ecological literacy. Nowadays, this is very important, because the teacher has always been a key figure in the formation of environmental competence of future generations. Therefore, in the professional training of students - future primary school teachers on the basis of the Pedagogical College, their knowledge, skills and abilities in environmental education, culture and readiness for environmental and environmental work with children, environmental competence is an important component in training.

The peculiarities of formation of ecological competence of students by the future teacher of the New Ukrainian school are covered in the work. Methods and forms of organization of educational activity during the study of the subject of the natural cycle are determined, as a method of teaching the integrated course "I explore the world" in the conditions of 
pedagogical college. Systematic approaches, professional-oriented activity, the principle of expediency and readiness for perception of ecological education and levels of ecological competence of future primary school teachers are formed. The influence of innovative technologies in the study of the integrated course on the state of ecological competence of future graduates of the pedagogical college is investigated.

Key words: competence, ecological competence of primary school teachers, state standard of primary education, New Ukrainian school, integrated course "I explore the world".

Постановка проблеми. У зв'язку зі швидким темпом розвитку суспільства та з впровадженням великої кількості новітніх технологій в освітній процес від освіти вимагають впровадження певних змін. Сьогодні триває вже третій рік оновлення змісту початкової освіти, в якому застосовується оптимальність середовища до навчання, гармонійного розвитку здобувача освіти, відкриття його здібностей. Відповідно, одним з головних питань у реформуванні освіти $\epsilon$ проблема формування екологічної компетентності особистості, яка зможе застосовувати набуті знання на практиці та під час розв'язання конкретних життєвих ситуацій. Особливе місце приділяється питанню, яке викликане кризовою ситуацією у сфері відносин «людина - суспільство». Також можна зазначити, що формування екологічної культури людини починається ще 3 дошкільного та молодшого шкільного віку, тому дуже зростає потреба у вчителеві, який зможе на науково-теоретичному рівні вирішувати завдання, а особливо 3 питань екологічного виховання молодших учнів.

Аналіз досліджень. Проблемі компетентності присвячено багато наукових праць. Проблемі формування екологічної компетентності школярів та їх виховання приділено увагу в працях В.В.Вербицького, В. В. Маршицької, О. І. Пометун. Значний внесок у запровадження компетентнісного підходу в освіту внесли такі відомі вчені, як Н. М. Бібік, О. I. Пометун, О. Я. Савченко та інші. В працях Г. А. Пустовіт, О. Л.Пруцаковазазначаються основні засади та особливості формування компетентностей, також ці автори аналізують поняття екологічної культури та приділяють увагу поняттю «екологічна компетентність особистості». Але, попри велику кількість публікацій, у педагогічній науці не достатньо висвітлена проблема формування екологічної компетентності у закладах вищої освіти.

Мета статті полягає в дослідженні реалізації екологічної компетентності майбутніх вчителів початкової освіти в процесі вивчення дисципліни природничого циклу на прикладі предмету «Методика навчання інтегрованого курсу “Я досліджую світ”» на базі педагогічного коледжу.

Виклад основного матеріалу. Сьогодні перед педагогічними закладами фахової передвищої освіти стоїть завдання щодо підготовки конкурен- тоспроможних та компетентних вчителів початкової школи на основі формування ключових компетентностей. (Державний стандарт початкової освіти, 2018: 92).

Під час впровадження Нової української школи передбачений новий зміст освіти, який заснований на формуванні компетентностей й наскрізних умінь, необхідних для самореалізації особистості.

Тому у процесі оновлення змісту освіти, переходу від початкової ланки освіти - знаннєвого компонента, до компетентнісного підходу майбутні вчителі початкової школи потребують оновленої науково-теоретичної підготовки до формування в учнів початкової школи відповідних компетенцій. Як висвітлено в Концепції «Нової української школи», компетентність - це динамічна комбінація знань, способів мислення, поглядів, цінностей, навичок, умінь, інших особистих якостей, що визначає здатність особи успішно провадити професійну та/або подальшу навчальну діяльність».

На підставі змін ми можемо визначити, що ключові компетентності на всіх етапах навчання мають свою рівнозначність. Тому кожна освітня галузь - мовно-літературна, математична, природнича, технологічна, інформатична, соціальна і здоров'язбережувальна, фізкультурна, громадянська та історична, мистецька, фізкультурна - має в собі такий освітній потенціал, який буде реалізований наскрізно та необхідний для формування кожної із зазначених ключових компетентностей 3 предмета чи інтегрованого курсу (Бібік, 2019: 16).

Iз прийняттям нового Державного стандарту початкової освіти на екологічну освіту покладаються великі надії щодо формування у дітей відповідного екологічного мислення, високої екологічної культури, екологоцентричного підходу до взаємин між людиною в природою. Це все зумовило необхідність формування в учнів початкових класів обгрунтованої екологічної поведінки у природі, оволодіння елементарними дослідницькими вміннями. (Андрусенко, 2019: 199). Екологічна компетентність реалізується в новому інтегрованому курсі «Я досліджую світ», де поєднуються такі освітні галузі, як громадянська та історична, соціальна та здоров'язбережувальна й природнича. Метою навчальної програми цього курсу $\epsilon$ особистісний розвиток молодших школярів на 
основі формування цілісного образу світу в процесі засвоєння різних видів соціального досвіду.

Одним із складників процесу підготовки майбутнього вчителя для викладання в Новій українській школі $є$ екологічна компетентність. Ця компетентність містить екологічні знання, уміння та навички раціонально користуватися природними ресурсами, брати участь у вирішенні екологічних проблем, усвідомлювати вплив своїх дій на навколишнє середовище, що в подальшому забезпечить успішність формування екологічної компетентності в молодших школярів.

Тому дуже актуальним для Нової української школи є завдання підготувати майбутніх вчителів початкової школи до екологічного виховання у процесі вивчення природничих дисциплін на базі педагогічного коледжу. Причому варто зробити акцент саме на розумінні компетентнісного підходу і ключових компетентностей у процесі формування екологічної компетентності у майбутніх фахівців початкової освіти.

У процесі оновлення змісту освіти початкової школи відбулися зміни і в закладах фахової підготовки майбутніх вчителів початкової школи. Так, у навчальних планах Дніпровського педагогічного коледжу зі спеціальності 013 Початкова освіта 32018 року вводяться нові предмети природничого циклу, одним 3 яких є інтегрований курс «Методика навчання предмету “Я досліджую світ”», в якому зроблено акцент на принципі компетентнісно-орієнтованого підходу навчання. На основі цього розроблена навчальна програма 3 предмету «Методика навчання "Я досліджую світ"», де викладання даної дисципліни відбувається 3 урахуванням екологізації освітнього процесу і головна мета - навчити використовувати отримані знання на практиці.

Вивчення курсу «Методика навчання предмету “Я досліджую світ”» сприяє розширенню та поглибленню уявлень про природні та соціальні об'єкти та явища, допомагає оволодіти новими знаннями про природу, людину та суспільство. Цей курс вивчається як пропедевтична частина для формування цілісної картини світу в його єдності природи і суспільства.

Особливу роль відіграє викладач педагогічного коледжу, тому що він починає формувати у здобувачів освіти мотивацію до навчання, до набуття природничої та екологічної компетентності i допомагає усвідомити важливість вивчення при- родничих дисциплін для подальшого життя та у професійній діяльності.

Здобувачі освіти мають зрозуміти, що такий курс, як «Я досліджую світ», $є$ важливим у житті, оскільки він формує систему інтегрованих знань про цілісний образ світу, про суспільство, про способи дослідницької поведінки та здатність розв'язувати практичні задачі.

Дуже велика мотивація здобувачів освіти у цьому курсі приділяється формуванню екологічної компетентності, бо здобувач освіти починає заглиблюватися у вивчення дисципліни, пізнаючи конкретні наукові, педагогічні і спеціальні знання та розширює свій світогляд. Особливою є мотивація з прагненням стати високоосвіченим спеціалістом, з умінням критично мислити і самореалізуватися. Тому, крім аудиторних занять з цієї дисципліни, ми використовували різноманітні новітні технології, такі як дискусії, анкетування, екскурсії на природі, спостереження, дослідження, створення власних проєктів та лепбуків 3 застосуванням екологічної компетентності.

Для вирішення завдань Концепції Нової української школи та ефективного формування екологічної компетентності в молодших школярів майбутні вчителі мають використовувати отримані у коледжі вміння та навички. 3 цією метою доцільно використовувати можливості шкільного краєзнавчого куточка, куточка живої природи, науково-дослідної ділянки, екскурсій у природу, презентацій та відео.

Майбутній вчитель після вивчення курсу має розробляти інтегрований зміст та проводити різні за структурою уроки інтегрованого курсу «Я досліджую світ» 3 впровадженням екологічної компетентності, організовувати діяльність дітей ігровими методами, створювати різноманітні завдання дослідницького характеру, добирати дидактичний інструментарій, вчити розв'язувати практичні завдання у життєвих ситуаціях, визначати екологічну компетентність молодших школярів.

Висновки. На основі цього можемо зробити висновок, що більшість здобувачів освіти педагогічного коледжу мають достатній рівень сформованої екологічної компетентності в процесі викладання інтегрованого курсу «Я досліджую світ» та можуть застосовувати на практиці новітні форми та методи роботи, що забезпечують реалізацію компетентнісного підходу в умовах удосконалення освітнього процесу. 


\section{СПИСОК ВИКОРИСТАНИХ ДЖЕРЕЛ}

1. Андрусенко I. В. Реалізація екологічної компетентності учнів початкових класів засобами інтегрованого курсу «Я досліджую світ», НЕНЦ, Всеукраїнська серпнева конференція «Педагогічний пошук - 2019». 2019. С. 198-202.

2. Войтович А. Ю. Екологічне виховання учнів початкових класів загальноосвітньої школи (друга половина XX століття) : автореф. дис. . канд. пед. наук : 13.00.01. Дрогобич, 2016. 20 с.

3. Грошовенко О. П. Екологічна освіта і виховання молодших школярів: навчально-методичний посібник для студентів денної та заочної форми навчання за напрямом підготовки «Початкова освіта». Вінниця : Нілан ЛТД, 2017.270 с.

4. Коваль В. О., Погасій І. О. Експериментальне дослідження стану екологічної компетентності майбутніх учителів початкової школи в контексті НУШ. Збірник наукових працьь «Педагогічні науки». Секція 4. Теорія і методика професійної освіти. 2018. Том 1 № 85. С. 108-111.

5. Концептуальні засади реформування середньої школи. URL: https://mon.gov.ua/storage/app/media/zagalna\%20 serednya/nova-ukrainska-shkola-compressed.pdf (дата звернення: 166.11.2020).

6. Коробчук Л. Формування екологічного світогляду як складова підготовки майбутніх фахівців - екологів, Наукові записки Тернопільського національного педагогічного університету. Серія: педагогіка. 2009. URL: https:// cyberleninka.ru/article/n/formuvannya-ekologichnogo-svitoglyadu-yak-skladova-pidgotovki-maybutnih-fahivtsiv-ekologiv.

7. Малицька О. В. Формування культури професійної діяльності майбутніх учителів початкової школи на основі компетентнісного підходу. Збірник наукових пращь БДПУ. № 2. Бердянськ, 2009. 272с.

8. Нова українська школа : порадник для вчителя / за заг. ред. Н. М. Бібік. Київ : Літера ЛТД, 2019. 208 с.

9. Про освіту: закон України від 05.09.2017 № 2145-VIII. URL: http://zakon5.rada.gov.ua/laws/show/2145-19. (дата звернення: 16.11.2020).

10. Про схвалення Концепції реалізації державної політики у сфері реформування загальної середньої освіти «Нова українська школа» на період до 2029 року: Розпорядження КМУ від 14 грудня 2016 p. № 988-p. URL: https://zakon.rada.gov.ua/laws/show/988-2016-\%D1\%80\#Text. (дата звернення: 16.11.2020).

11. Пруцакова О. Л. Сутність та види екологічної компетентності особистості. Теоретико-методичні проблеми виховання дітей та учнівської молоді: зб. наук. праць. Вип. 8. Кн. 2. Київ, 2005. 392 с.

12. Пустовіт Н. А. Сутнісні характеристики екологічної компетентності школярів. Педагогічні науки : зб. наук. працьь. Херсон, 2005. $186 \mathrm{c.}$

13. Січко I. Екологічна компетентність як професійна складова підготовки майбутніх вчителів початкових класів. Проблеми підготовки сучасного вчителя. № 7. 2013. URL: http://irbis-nbuv.gov.ua/cgi-bin/irbis_nbuv/cgiirbis_64. exe?C21COM=2\&I21DBN=UJRN\&P21DBN=UJRN\&IMAGE_FILE_DOWNLOAD=1\&Image_file_name $=\overline{\text { PDF } /}$ ppsv_2013_7_33.pdf. (дата звернення 16.11.2020).

14. Типові освітні програми для закладів загальної середньої освіти: 1-2 класи (Державний стандарт початкової освіти). Київ. ТД «Освіта-Центр+», 2018. С. 92-121.

\section{REFERENCES}

1. Andrusenko I. V. Realizaciya ekologichnoyi kompetentnosti uchniv pochatkovy’h klasiv zasobamy' integrovanogo kursu «Ya doslidzhuyu svit» [Realization of ecological competence of pupils of initial classes by means of the integrated course "I explore the world"]. Kiev. NENCz, Vseukrayins'ka serpneva konferenciya "Pedagogichy'j poshuk - 2019", 2019, pp. 198-202 [in Ukrainian].

2. Vojtovy'ch A. Yu. Ekologichne vy'hovannya uchniv pochatkovy'h klasiv zagal'noosvitn'oyi shkoly' (druga polovy'na XX stolittya): avtoref. dy's. kand. ped. nauk: 13.00.01 [Ecological education of primary school students (second half of the XX century): author's ref. dis. Cand. ped. Science: 13.00.01]. Drogobich., 2016, p. 20 [in Ukrainian].

3. Groshovenko O. P. Ekologichna osvita i vy'hovannya molodshy'h shkolyariv: navchal'no-metody'chny'j posibny'k dlya studentiv dennoyi ta zaochnoyi formy' navchannya za napryamom pidgotovky" "Pochatkova osvita". [Ecological education and upbringing of junior schoolchildren: a textbook for full-time and part-time students in the field of "Primary Education"]. Vinnytsia, 2017, p.270 [in Ukrainian].

4. Koval' V. O., Pogasij I. O. Ekspery'mental'ne doslidzhennya stanu ekologichnoyi kompetentnosti majbutnih uchy'teliv pochatkovoyi shkoly'v konteksti NUSh. Zbirny’k naukovy’h pracz' „Pedagogichni nauky”” Sekciya 4 Teoriya i metody'ka profesijnoyi osvity'. [Experimental study of the state of ecological competence of future primary school teachers in the context of NUS. Collection of scientific works "Pedagogical sciences" Section 4 Theory and methods of vocational education], 2018, pp. 108-111 [in Ukrainian].

5. Konceptual'ni zasady' reformuvannya seredn'oyi shkoly, 2016. [in Ukrainian]. [Conceptual principles of secondary school reform]. URL: https://mon.gov.ua/storage/app/media/zagalna\%20serednya/nova-ukrainska-shkola-compressed.pdf. (data zvernennya: 26.11.2020).

6. Korobchuk L. Formuvannya ekologichnogo svitoglyadu yak skladova pidgotovky' majbutnih faxivciv - ekologiv, Naukovi zapy'sky' Ternopil's'kogo nacional'nogo pedagogichnogo universy'tetu, 2009. [in Ukrainian]. [Formation of ecological worldview as a component of training of future specialists - ecologists, Scientific notes of Ternopil National Pedagogical University. Series: pedagogy] URL: https://cyberleninka.ru/article/n/formuvannya-ekologichnogo-svitoglyadu-yak-skladova-pidgotovki-maybutnih-fahivtsiv-ekologiv (data zvernennya 26.11.2020).

7. Maly'cz'ka O.V. Formuvannya kul'tury' profesijnoyi diyal'nosti majbutnix uchy'teliv pochatkovoyi shkoly' na osnovi kompetentsnogo pidhodu. Zbirny'k naukovy'h pracz. [Forming a culture of professional activity of future primary school teachers on the basis of a competent approach. Collection of scientific works of BSPU № 2]. Berdyansk, 2009, p. 272. [in Ukrainian]. 
8. Nova ukrayins'ka shkola: poradny'k dlya vchy'telya / za zag. red. N. M. Bibik. [New Ukrainian school: a guide for teachers / for general. ed. NM Bibik] Kyiv. Litera LTD, 2019, p.208 [in Ukrainian].

9. Pro osvitu: zakon Ukrayiny’ vid 05.09.2017 № 2145-VIII, 2017 [in Ukrainian]. [On education: the law of Ukraine of 05.09.2017 № 2145-VIII]. URL: http://zakon5.rada.gov.ua/laws/show/2145-19. (data zvernennya: 26.11.2020).

10. Pro shvalennya Koncepciyi realizaciyi derzhavnoyi polity'ky' u sferi reformuvannya zagal'noyi seredn'oyi osvity' "Nova ukrayins’ka shkola" na period do 2029 roku: Rozporyadzhennya KMU vid 14 grudnya 2016 r. № 988-r, 2016, [in Ukrainian]. [On approval of the Concept for the implementation of state policy in the field of reforming general secondary education "New Ukrainian School" for the period up to 2029: Order of the Cabinet of Ministers of December 14, 2016 № 988-r]. URL: https://zakon.rada.gov.ua/laws/show/988-2016-\%D1\%80\#Text. (data zvernennya: 16.11.2020).

11. Pruczakova O. L. Sutnist' ta vy'dy' ekologichnoyi kompetentnosti osoby'stosti. [The essence and types of ecological competence of the individual. Theoretical and methodological problems of education of children and students: collection of scientific works]. Kyiv, 2005, p. 392 [in Ukrainian].

12. Pustovit N. A. (2005). Sutnisni haraktery'sty'ky' ekologichnoyi kompetentnosti shkolyariv. [Essential characteristics of ecological competence of schoolchildren. Pedagogical sciences: collection of scientific works]. Kherson, 2005, p.186 [in Ukrainian].

13. Sichko I. Ekologichna kompetentnist' yak profesijna skladova pidgotovky' majbutnih vchy'teliv pochatkovy'h klasiv, 2013 [in Ukrainian]. [Environmental competence as a professional component of training future primary school teachers. Problems of modern teacher training № 7]. URL: http://irbis-nbuv.gov.ua/cgi-bin/irbis_nbuv/cgiirbis_64.exe?C21COM=2\& I21DBN=UJRN\&P21DBN=UJRN\&IMAGE_FILE_DOWNLOAD=1\&Image_file_name=PDF/ppsv_2013_7_33.pdf. (data zvernennya 16.11.2020).

14. Ty'povi osvitni programy' dlya zakladiv zagal'noyi seredn'oyi osvity': 1-2 klasy' (Derzhavny'j standart pochatkovoyi osvity') (2018). [Typical educational programs for general secondary education: 1-2 grades (State standard of primary education)]. Kyiv, 2018, pp. 92-121 [in Ukrainian]. 